\title{
Endothelin: link between the primary placental causes and the secondary systemic endothelial dysfunction in pathophysiology of pre-eclampsia
}

\begin{abstract}
Objectives: In order to gain more insight into the mechanisms underlying pre-eclampsia, we evaluated the effect of endothelin-1, nitric oxide and inflammatory cytokines in pathophysiology of pre-eclampsia.

Methods: This cross-sectional study included 60 pregnant women diagnosed with Preeclampsia and 60 healthy pregnant women. Their blood samples were analyzed for nitric oxide (NO) by greiss reaction, tumor necrosis factor alpha (TNFÎI \pm ), interleukin-6 (IL -6), interleukin-2 (IL-2) and endothelin-1 (ET-1) by ELISA

Results: Pre-eclamptic group showed a significant decreased level of serum NO and increased level of serum TNFÎ \pm , IL-6, IL-2 and ET-1 compared to control group. A significant positive correlation was seen between serum Endothelin-1 and IL-2 in preeclamptic group.

Conclusion: In response to chronic reduction in uterine perfusion due to inadequate placentation, TNFI \pm and IL-2 activates the endothelin system in placenta and viceversa whereas IL-6 inhibits endothelium dependent NO-cyclic guanine monophosphate mediated relaxation pathway leading to development of systemic hypertension. This further compromises feto-placental circulation. It might be concluded, that ET-1 may be the key link between the primary placental causes and the secondary systemic endothelial dysfunction. ET-1 along with inflammatory cytokine levels may serve as a prognostic parameter, indicating the possibility of development of pre-eclampsia.
\end{abstract}

Volume 2 Issue 3 - 2015

\author{
Archana Singh,' Chitra Raghunandan, ${ }^{2}$ \\ Jayashree Bhattacharjee ${ }^{3}$ \\ 'Department of Biochemistry, All India Institute of Medical \\ Sciences, India \\ ${ }^{2}$ Department of Obstetrics and Gynecology, Lady Hardinge \\ Medical College, India \\ ${ }^{3}$ Vardhman Mahavir Medical College, India
}

\author{
Correspondence: Archana Singh, Department Of \\ Biochemistry, All India Institute of Medical Sciences, Delhi \\ -I l 0029, India, Tel 9868450254,
}

Email archanasinghmamc@gmail.com

Received: April 15, 2015 | Published: June 09, 2015

Keywords: pre-eclampsia, endothelin-1, nitric oxide, TNFÎ \pm , IL-2, IL-6

Abbreviations: NO, nitric oxide; TNFÎ \pm , tumor necrosis factor alpha; IL-6, interleukin-6; IL-2, interleukin-2; ET-1, endothelin-1; Th-2, T helper-2; Th-1, T helper-1

\section{Introduction}

A normotensive pregnancy depends upon the balance between vasoconstrictors and vasodilators. In pre-eclampsia it is thought that vasodilators like nitric oxide (NO) is decreased ${ }^{1}$ and endothelin (ET1), one of the most potent vasoconstrictors is increased. ${ }^{2,3}$ ET-1 causes vascular smooth muscle contraction by increasing the formation of angiotensin II to which there is an increase vasopressor response in pre-eclampsia. ${ }^{4}$ ET-1 also stimulates in vitro adherence of leukocytes to endothelium, inducing the expression of adhesion molecules on endothelial cells and leukocytes suggesting a proinflammatory action. ${ }^{5}$

Placental and decidual tissues from normal pregnancies have been shown to express both pro-and anti-inflammatory cytokines. In normal pregnancy, particularly, at the maternal- fetal interface, anti-inflammatory cytokines produced by $\mathrm{T}$ helper- 2 (Th-2) cells predominate, regulating trophoblast cell growth, differentiation and invasion for embryo implantation. ${ }^{6}$ Endothelial dysfunction, present in pre-eclampsia, may cause abnormal immune $\mathrm{T}$ helper1(Th-1) activation, which compromises uteroplacental perfusion and perpetuates further vascular damage. ${ }^{7}$

Till date, little information is available on the mechanism of development of pre-eclampsia. It is still not clear what brings about the expression of proinflammatory cytokines and release of ET-1 causing hypertension or whether it is a consequence or effect or vice versa. In the present study, we examined the role of ET-1 and inflammatory cytokines in bringing endothelial damage and changes in pre-eclampsia.

\section{Materials and methods}

\section{Study design}

This crossectional study included 120 antenatal women attending antenatal clinics and wards of a tertiary care hospital in New Delhi, India. The women were divided into two groups. Study group consisted of 60 pregnant women diagnosed with pre-eclampsia based upon criteria laid by international society for the study of hypertension in pregnancy. ${ }^{8}$ Control group consisted of 60 healthy pregnant women with no signs of pre-eclampsia on routine antenatal examination. The age group of women enrolled in both the groups was 20-30 years. During antenatal visit, women attending antenatal clinics are routinely screened for any rise in blood pressure and other parameters. 24 hour urine sample were assessed if the blood pressure was found to be elevated. The inclusion criteria for study group was a blood pressure of more than $140 / 90 \mathrm{mmHg}$ and 24 hour urine protein to be $\geq 300 \mathrm{mg}$ or $\geq 1+$ dipstick after gestational age of $>20$ weeks. Both the groups were matched for age, parity and period of gestation.

Women with chronic hypertension, gestational hypertension without proteinuria, chronic kidney disease, and period of gestation 
less than 20 weeks, TORCH infections, major medical illness like diabetes mellitus, chronic renal failure, heart disease, and severe anemia were excluded. Pregnant women with transverse lie, fetal malformation, multiple pregnancy, smoking and history of intake of arginine tablets were also excluded from the study. Patients with any other chronic inflammatory disorder and any active foci of infection were also excluded. Various tests were done to rule out the same.

Women in both the groups were primigravidae and the gestational age during sampling was between 20 to 40 weeks. After approval from institutional ethical committee, a detailed informed consent was taken from all the participants in simple language at the time of enrolment.

\section{Sample collection and analysis}

Eight milliliters of venous blood samples were collected from both the groups. After centrifugation of clotted blood, separated serum was aliquoted into five separate tubes for estimation of various parameters under study. Samples were stored at -20 degree Celsius until further processing. Samples were analysed in batches of 30 each after thawing them at 2-8 degree Celsius for an hour followed by at room temperature for another hour.

\section{Estimation of nitric oxide}

NO was measured indirectly by estimating nitrite in the serum samples. Nitrite is a stable and non volatile product of NO. This assay relies on a diazotization reaction described originally by greiss. We have used modified method of Mathew et al. ${ }^{9}$ Greiss reaction is based on the principal of formation of a magenta colored azo dye which can be measured colorimetrically at $543 \mathrm{~nm}$. Under low $\mathrm{pH}$ nitrites present in the blood undergoes diazotization with sulfanilamide to form diazonium salt. This diazonium salt then couples to heterocyclic amine of N- (1-napthyl) ethlenediamine (Griess reagent) to form a magenta colored compound. This procedure may be interfered with presence of serum proteins. So, deproteinization of samples was done with methanol, which does not interfere with the reaction.

\section{Estimation of serum endothelin-I}

Levels of ET-1 (endothelin-1) were determined by solid phase sandwich enzyme linked immunosorbent assay (DRG International Inc., USA). The assay utilizes specific anti human endothelin antibody coated onto the wells of microtiter plates. Serum samples $(100 \mu \mathrm{L})$ and standards $(100 \mu \mathrm{L})$ were pipetted into appropriate microtiter wells, and the assay was performed according to manufacturer's instructions. The sensitivity of ELISA ET- 1 is $0.14 \mathrm{pg} / \mathrm{ml}$ and the upper limit of detection is $200 \mathrm{pg} / \mathrm{ml}$.

\section{Estimation of inflammatory cytokines}

Levels of TNF $\alpha$, IL-6 and IL-2 were determined based upon principle of solid phase sandwich enzyme linked immunosorbent assay using commercial kit (DIACLONE Research, BESANCON Cedex, France). The assay utilizes specific anti human TNF $\alpha$, IL-6 and IL-2 antibody coated onto the wells of microtiter plates. Serum samples $(100 \mu \mathrm{L})$ and standards $(100 \mu \mathrm{L})$ were pipetted into appropriate microtiter wells, and the assay was performed according to manufacturer's protocol. The sensitivity of ELISA TNF $\alpha$, IL-6 and IL-2 system is $8.0,2.0$ and $14.0(\mathrm{pg} / \mathrm{ml})$ respectively and the upper limit of detection is 800,200 and $1000(\mathrm{pg} / \mathrm{ml})$ respectively.

\section{Statistical analysis}

All data are expressed as mean \pm SEM and statistical analysis was conducted using SPSS statistical package, version 19.0 (SPSS Inc., Chicago, IL, USA). A p-value $<0.05$ was considered as significant. For normally distributed data, student t-test was used. To analyze the relation between endothelin-1 and pro-inflammatory cytokines in the study and control group Pearson's correlation was applied.

\section{Results}

Serum NO levels were found to be significantly lower in preeclamptic women $(66.076 \pm 3.32 \mu \mathrm{mol} / \mathrm{L})$ compared to normotensive pregnant women $(96.344 \pm 4.04 \mu \mathrm{mol} / \mathrm{L})(\mathrm{p}<0.05)$ (Table 1). The difference in the mean value of serum ET-1(20.79 $\pm 3.11 / 4.18 \pm$ 1.67), TNF- $\alpha(235.4 \pm 35.10 / 39.60 \pm 4.10)$, IL-2 $(497 \pm 44.35 / 79 \pm$ $1.04)$ and IL-6(29.49 $\pm 7.66 / 2.77 \pm 0.21)$ between the pre-eclamptic group and normotensive group was found to be highly significant $(\mathrm{p}<0.001)$ (Table 1). No significant correlation was found between serum ET-1, IL-6 and TNF- $\alpha$ in both the study and control group. In the study group, a significant positive correlation was found between serum ET-1 and IL-2 ( $\mathrm{p}=0.02)$ (Table 2).

Table I Levels of nitric oxide, endothelin-I and inflammatory cytokines between study and control group

\begin{tabular}{llll}
\hline \multirow{2}{*}{ Parameter } & \multicolumn{2}{l}{ Study Group } & \multicolumn{2}{l}{ Control Group } & \multirow{2}{*}{ PValue } \\
\cline { 2 - 3 } & (Mean \pm SEM) & (Mean \pm SEM) & \\
\hline NO $(\mu \mathrm{mol} / \mathrm{L})$ & $66.07 \pm 3.32$ & $96.34 \pm 4.04$ & $<0.05$ \\
Endothelin $(\mathrm{pg} / \mathrm{mL})$ & $20.79 \pm 3.11$ & $4.18 \pm 1.67$ & $<0.001$ \\
$\mathrm{TNF} \alpha(\mathrm{pg} / \mathrm{mL})$ & $235.40 \pm 35.10$ & $39.60 \pm 4.10$ & $<0.001$ \\
$\mathrm{IL}-2(\mathrm{pg} / \mathrm{mL})$ & $497 \pm 44.35$ & $79 \pm 1.04$ & $<0.001$ \\
$\mathrm{IL}-6(\mathrm{pg} / \mathrm{mL})$ & $29.49 \pm 7.16$ & $2.77 \pm 0.21$ & $<0.001$ \\
\hline
\end{tabular}

Table 2 Correlation of serum Endothelin with TNF $\alpha$, IL-6 and IL-2 in study and control group

\begin{tabular}{|c|c|c|c|}
\hline \multirow[b]{2}{*}{ Group } & \multirow{2}{*}{$\begin{array}{l}\text { Inflammatory } \\
\text { Cytokines }\end{array}$} & \multicolumn{2}{|l|}{ Endothelin } \\
\hline & & $\begin{array}{l}\text { Pearson } \\
\text { Correlation }\end{array}$ & $\begin{array}{l}\text { Significance } \\
\text { ( } 2 \text { tailed) }\end{array}$ \\
\hline \multirow{3}{*}{ Study Group } & IL-2 & $0.314^{*}$ & 0.026 \\
\hline & IL-6 & -0.212 & 0.139 \\
\hline & TNF $\alpha$ & 0.183 & 0.204 \\
\hline \multirow{3}{*}{ Control Group } & IL-2 & -0.017 & 0.904 \\
\hline & IL-6 & 0.197 & 0.171 \\
\hline & TNF $\alpha$ & 0.128 & 0.376 \\
\hline
\end{tabular}

${ }^{*}$ Correlation is significant at the 0.01 level (2- tailed).

\section{Discussion}

Identification of factors for causing pre-eclampsia could aid substantially in the understanding of this important public health problem and provide clues for its prevention and treatment. Preeclampsia has gained more importance because of its association with increased risk of cardiovascular disease in later life, indicating the persistence of certain factors on long-term basis. ${ }^{10}$

In the present study, we found a significant increase in ET-1 levels in pre-eclamptic group in accordance with finding of other researchers., 
Injury to placental endothelial cells produce several mediators, ${ }^{11}$ among them ET-1 is one of the most potent vasoconstrictors. It may have cytotoxic effects on trophoblast and trigger oxidant substance release from human placenta that enter into the maternal circulation and contribute to cellular membrane damage and widespread endothelial dysfunction. ${ }^{12}$

Cytokines are known to play important role in maintenance of normal pregnancy and as well as development of pathological states. Supporting a role for inflammatory cytokines in present study are findings of Th- 1 predominant profile i.e. elevated serum TNF $\alpha$, IL-6 and IL-2 levels in preeclamptic women. ${ }^{1,7,13}$ However there have been conflicting reports in the literature regarding no significant change in inflammatory cytokines ${ }^{14,15}$ in pre-eclampsia as compared to normal pregnancy. The present study supports the hypothesis of altered immune response in pre-eclampsia and suggests that dysregulation of cytokine expression occurs in pre-eclampsia with increased levels of pro-inflammatory cytokines. Inadequate trophoblast invasion and failure of physiologic remodeling of spiral arteries of placenta in preeclampsia stimulates production of IL1 $\beta$ and in turn overproduction of inflammatory Th1 cytokines (TNF $\alpha$, IL-2, IL-6) causing endothelial damage, poor placentation and excessive maternal inflammatory response. ${ }^{16}$

In our study we found a positive correlation between ET-1 and $\mathrm{TNF} \alpha$ though it was not found to be significant. TNF $\alpha$ probably contributes to altered prostaglandin production and impaired balance between vasomotor regulating factors such as $\mathrm{NO}$ and endothelin- $1 .{ }^{17}$ TNF- $\alpha$ is also thought to activate the endothelin system in placental, renal, and vascular tissues in PE. ${ }^{18}$ Significant positive correlation was observed between levels of ET-1 and IL-2 in the present study, which indicates that IL-2 along with endothelin might be a possible mediator of increased vascular resistance during pre-eclampsia. ET-1 also triggers the release of interleukin-6, suggesting a pro-inflammatory action $^{5}$ though we did not find any significant association between the two. Thus increased ET-1 via increased IL-6 levels contributes to increased vascular resistance by counteracting NO mediated relaxation pathway in systemic vessels in pre-eclampsia. ${ }^{1}$

Previous in vitro studies have shown a positive correlation between ET-1 and Th-1 inflammatory cytokines also suggested that ET- 1 could be involved in inflammatory events causing a Th1:Th2 imbalance in preeclampsia. ${ }^{19}$ ET-1 induces leukocyte adhesion to cultured endothelial cells, stimulates cytokines release from isolated leukocytes and promotes vascular permeability by an effect on the expression of adhesive molecules on the neutrophil surface. ${ }^{5}$ These findings have potential importance in the pathophysiology of endothelin-1-increased states like in Pre-eclampsia. These findings suggest that inflammatory cytokines along with ET-1 elevates blood pressure during pregnancy by activating multiple neurohumoral and endothelial factors but it is still not clear that whether endothelin triggers release of inflammatory cytokines or vice-versa

\section{Conclusion}

Pre-eclampsia is associated with a increased levels of circulating inflammatory cytokines and ET-1. There may be interrelated and interlocking positive feedback loops by which cytokines promote release of endothelin or vice-versa from endothelial cells leading to systemic endothelial dysfunction (Figure 1). The decrease in vasodilatation is influenced by the presence of endothelin and inflammatory cytokines which inhibits NO mediated relaxation pathway in systemic vessels in pre-eclampsia. ET-1 along with inflammatory cytokines level may serve as a prognostic parameter, indicating the possibility of development of pre-eclampsia.

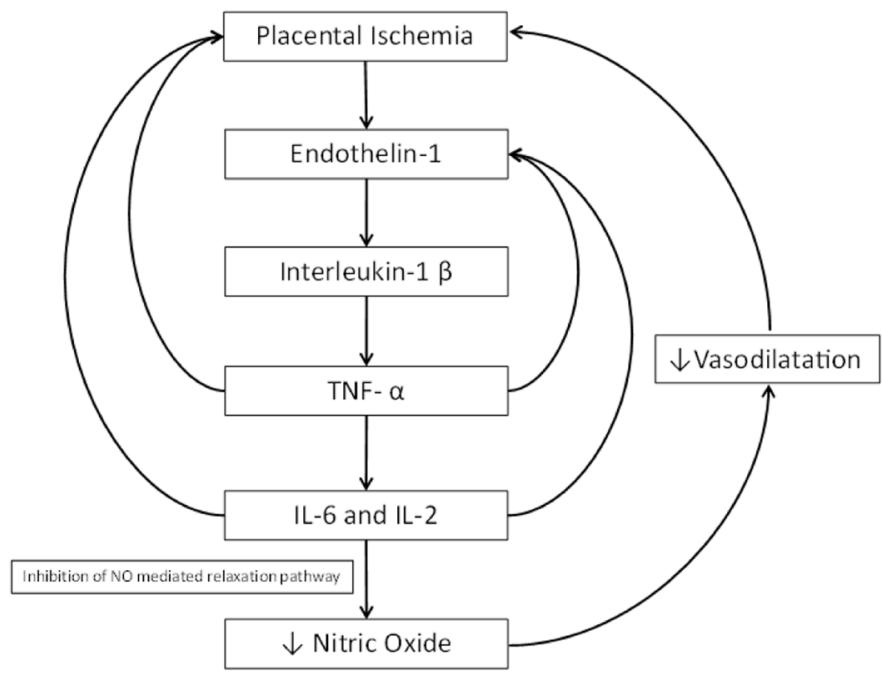

Figure I Potential mechanism in development of pre-eclampsia: Interlocking positive feedback loops linking nitric oxide, endothelin-I and inflammatory cytokines leading to decrease in vasodilatation and development of vasoconstriction in pathophysiology of pre-eclampsia.

\section{Acknowledgments}

None.

\section{Conflicts of interest}

The authors declare there is no conflict of interests.

\section{References}

1. Singh A, Sharma D, Raghunandan C, et al. Role of Inflammatory Cytokines and eNOS Gene Polymorphism in Pathophysiology of PreEclampsia. Am J Reprod Immunol. 2010;63(3):244-251.

2. Taylor RN, Varma M, Teng NN, et al. Women with preeclampsia have higher plasma endothelin levels than women with normal pregnancies. $J$ Clin Endocrinol Metab. 1990;71(6):1675-1677.

3. Nova A, Sibai BM, Barton JR, et al. Maternal plasma level of endothelin is increased in preeclampsia. Am J Obstet Gynecol. 1991;165(3):724 727.

4. Yanagisawa M, Kuriraba H, Kimura S, et al. A novel potent vasoconstrictor peptide produced by vascular endothelial cells. Nature. 1998;332(6163):411-415.

5. López-Farré A, Riesco A, Espinosa G, et al. Effect of endothelin-1 on neutrophil adhesion to endothelial cells and perfused heart. Circulation. 1993;88(3):1166-1171.

6. Wegmann TG, Lin H, Guilbert L, et al. Bidirectional cytokine interactions in the maternal-fetal relationship: is successful pregnancy a TH-2 phenomenon? Immunol Today. 1993;14(7):353-356.

7. Freeman DJ, McManus F, Brown EA, et al. Short- and long-term changes in plasma inflammatory markers associated with pre-eclampsia. Hypertension. 2004;44(5):708-714.

8. Brown MA, Lindheimer MD, De Swiet M, et al. The classification of hypertensive disorder of pregnancy (ISSHP). Hypertens Pregnancy. 2001;20(1):IX-XIV. 
9. Mathew G, Glenda J, Jack L. Quantitation of nitrite and nitrate in extracellular fluids. Methods Enzymol. 1996;268:237-246.

10. Smith GC, Pell JP, Walsh D. Pregnancy complications and maternal risk of ischaemic heart disease, cohort study of 129,290 births. Lancet. 2001;357(9273):2002-2006.

11. Roberts JM, Hubel CA. Is oxidative stress the link in the two-stage model of pre-eclampsia? Lancet. 1999;354(9181):788-789.

12. Scalera F, Dittrich R, Beckmann MW, et al. Effect of endothelin-1 on intracellular glutathione and lipid peroxide availability and on the secretion of vasoactive substances by human umbilical vein endothelial cells. Eur J Clin Invest. 2002;32(8):556-562.

13. Jonsson $Y$, Ruber M, Matthiesen L, et al. Cytokine mapping of sera from women with pre-eclampsia and normal pregnancies. J Reprod Immunol. 2006; 70(1-2):83-91.

14. Ellis J, Wennerholm MB, Bengtsson A, et al. Levels of dimethylarginines and cytokines in mild and severe pre-eclampsia. Acta Obstet Gynecol Scand. 2001;80(7):602-608.
15. Madazli R, Aydin S, Uludag S, et al. Maternal plasma levels of cytokines in normal and preeclamptic pregnancies and their relationship with diastolic blood pressure and fibronectin levels. Acta Obstet Gynecol Scand. 2003;82(9):797-802.

16. Roberts JM, Redman CWG. Pre-eclampsia: more than pregnancy induced hypertension. 1993;341(8858):1447-1454.

17. Vural P. Nitric oxide/endothelin-1 in pre-eclampsia. Clinica Chimica Acta. 2002;317(1-2):65-70.

18. LaMarca BD, Ryan MJ, Gilbert JS, et al. Inflammatory cytokines in the pathophysiology of hypertension during preeclampsia. Curr Hypertens Rep. 2007;9(6):480-485.

19. Kuwajima T, Suzuki S, Yoneyama Y, et al. Relation between Plasma Endothelin 1 Levels and T Helper 1: T Helper 2 Cell Immunity in Women with Preeclampsia. Gynecol Obstet Invest. 2001;52(4):260-263. 